\title{
La forja de la izquierda peronista como cultura política a través de la trayectoria de John W. Cooke
}

\author{
The forging of the Peronist left as a political culture through the \\ trajectory of John W. Cooke
}

\author{
Valeria A. Caruso \\ Instituto de Historia Argentina y Americana "Dr. Emilio Ravignani", \\ Facultad de Filosofía y Letras, Universidad de Buenos Aires, \\ Consejo Nacional de Investigaciones Científicas y Técnicas, Argentina \\ caruso.valeria@gmail.com
}

\section{Resumen}

La crisis política abierta por el golpe de estado perpetrado por las Fuerzas Armadas en septiembre de 1955, y profundizada por los gobiernos semidemocráticos y dictatoriales que se sucedieron en el poder del estado hasta 1973, alteró sustancialmente el marco de representaciones y acción en la escena política local. En ese contexto se gestaron ideas y símbolos que incidieron en la reelaboración de distintas tradiciones políticas.

En este trabajo se analiza el proceso de articulación de la Izquierda peronista (IP) como cultura política a través del examen de la trayectoria política e intelectual de John William Cooke. A través de las prescripciones conceptuales elaboradas por Jean François Sirinelli para el estudio de las culturas políticas, y de la propuesta de abordaje de las fuentes escritas elaborada por Simona Cerutti, se examinan las núcleos políticos-conceptuales del pensamiento de Cooke que incidieron en la resignificación de las representaciones sobre el peronismo durante el periodo de la proscripción.

\section{Palabras Clave}

cultura política; izquierda peronista; John William Cooke; peronismo

\begin{abstract}
The political crisis caused by the coup d'état perpetrated by the Armed Forces in September 1955 , deepened by the semi-democratic and dictatorial governments that succeeded the state until 1973, substantially altered the framework of representations and actions on the local Argentinian? political scene. In this context, ideas and symbols were born influencing the re-elaboration of different political traditions.

This paper analyzes the process of articulation of the Peronist Left (IP) as a political culture through the examination of John William Cooke's political and intellectual trajectory. Through the conceptual prescriptions elaborated by Jean François Sirinelli for the study of political cultures, and the proposed approach of written sources elaborated by Simona Cerutti, we examine the political-conceptual nuclei of Cooke's thought that influenced the resignification of representations on Peronism during the proscription period.
\end{abstract}




\title{
La forja de la izquierda peronista como cultura política a través de la trayectoria de John W. Cooke
}

\author{
Keywords \\ political culture; Peronist Lef; John William Cooke; Peronism
}

\section{Introducción}

El golpe de estado perpetrado por las Fuerzas Armadas en septiembre de 1955 hizo estallar el sistema de representaciones políticas por entonces vigentes. El peronismo fuera del poder del Estado inicio un proceso de reformulación política forzado por la expulsión, persecución e inhibición "legal" de sus referentes, de sus organizaciones y de su simbología.

En este artículo se analiza cómo en el devenir de ese proceso político y, en relación con la coyuntura internacional, se fueron articulando paulatinamente nuevas prácticas, discursos y representaciones sobre el movimiento proscripto que posibilitaron la emergencia de la izquierda peronista (IP) como una cultura política, y la incidencia de la trayectoria política e intelectual de John William Cooke en su articulación. ${ }^{1}$ Por cultura política nos referimos a "un conjunto de representaciones que cohesionan a un grupo humano en el plano político, es decir una visión del mundo compartida, una lectura común del pasado, una proyección hacia el futuro, vivida en grupo. Esto desemboca, dentro del combate político cotidiano, en la aspiración a tal o cual forma de régimen político y de organización socioeconómica, al mismo tiempo que sobre normas, creencias y valores compartidos."2

Una mirada atenta a las instancias formativas de la IP permite evaluar una serie de elementos que están presentes desde sus comienzos y que, además de diferenciarla de otras izquierdas, ${ }^{3}$ fueron resignificados por distintos actores retrospectivamente, interpelados por la necesidad de intervenir en la coyuntura

\footnotetext{
${ }^{1}$ Si bien la denominación "Peronismo Revolucionario" fue utilizada por distintos actores durante el periodo que aborda este trabajo, consideramos que la misma no da cuenta de la magnitud de las mutaciones ideológicas, políticas y discursivas que se dieron en el interior del peronismo en las décadas del '60 y '70. Más aún si observamos que esta fuerza política se consideraba a si misma revolucionaria desde el mismo momento de su emergencia, y que incluso durante las décadas que aborda esta indagación los sectores más ortodoxos del movimiento ensalzaban el carácter revolucionario del peronismo (véase Juan Luis Besoky. La derecha peronista. Prácticas políticas y representaciones (1943-1976). La Plata, Tesis de doctorado, 2015). Para estos últimos, la gesta por hacer era la de forjar las condiciones para el retorno de Perón al poder, y así continuar con la transformación peronista interrumpida por el golpe de Estado de septiembre de 1955. Sin embargo, desde ese momento, comenzaron a estructurarse nuevas formar de entender el contenido revolucionario del peronismo, las cuales entablaron un entendimiento profundo con la realización de un socialismo nacional solo edificable desde el seno del movimiento proscripto.

${ }^{2}$ Jean François Sirinelli, "Elogio de lo complejo", en Jean-Pierre Rioux y Jean-François Sirinelli, Para una historia cultural. México, Taurus, 1999, p. 462.

3 En particular, de la denominada izquierda nacional de los '60. Es habitual encontrar en la bibliografía referida a las izquierdas de los ' 60 y'70 la homologación de las interpretaciones de Jorge Abelardo Ramos con las Cooke, a quienes autores como Norberto Galasso, los emparentan dentro de la Izquierda Nacional. Sin embargo, un análisis de sus perspectivas políticas permite diferenciarlas en relación al lugar de Perón y del peronismo en las proyecciones revolucionarias a emprender. Véase Norberto Galasso Cooke de Perón al Che. Una biografía política. Buenos Aires, Ediciones Nuevos Tiempos, 2005.
} 
política local para transformarla. Durante ese proceso se fueron gestando prácticas, símbolos e ideas que dieron forma a un peronismo de nuevo tipo, cimentando una activa comunidad de sentido que nutrió los contenidos y las formas de la IP como cultura política.

Al respecto, Serge Berstein ha planteado que el surgimiento de las culturas políticas está asociado a grandes traumatismos políticos que "en la medida en que cuestionan las identidades, provocaron efectivamente la mutación, el abandono de culturas políticas sólidamente instaladas o la adhesión a nuevas formas de culturas políticas." 4 Es decir, una cultura política emerge como un "conjunto de representaciones de carácter normativo" en un contexto de crisis política en el que se busca generar opciones con vista a recomponer o transformar el orden político en un momento determinado. Asimismo, ha advertido su carácter evolutivo y relacional con otras culturas políticas, en tanto éstas no pueden transformarse "si no es chocando de frente con las tradiciones de las cuales obtienen precisamente una parte importante de su fuerza". ${ }^{5}$ Otro aspecto señalado por el autor refiere a la doble dimensión de toda cultura política, en tanto "es al mismo tiempo un fenómeno individual, interiorizado por el ser humano, y un fenómeno colectivo compartido por grupos numerosos". 6

Es en ese intersticio entre lo individual y lo colectivo que resulta relevante recuperar la trayectoria de John William Cooke en el primigenio entramado de la IP como cultura política. Nos referimos a la paulatina configuración de una "comunidad de sentido" en permanente construcción atravesada por los avatares de la contingencia política argentina. De allí la necesidad de recurrir a referencias desde las cuales fundamentar/legitimar prácticas, discursos y representaciones sobre los significados del peronismo en un contexto interpelado por la incidencia de la revolución cubana, las luchas de "liberación nacional" del "tercer mundo", y el despliegue de la "guerra fría" a escala planetaria. Realizar esta operación, habilita considerar a la IP en la contingencia de su devenir en tanto tal, y observarla como una cultura política en gestación permanente, aunque estructurada en torno a ciertos principios políticos e ideológicos que se irán condensando y rearticulando en el desarrollo de una coyuntura política situada. De hecho, ésta comienza a gestarse como "una respuesta subversiva ante el desplazamiento del peronismo del poder estatal."7 Esta consideración permite recuperar tanto su dimensión contingente como la heterogeneidad de una cultura política porosa y conflictiva, signada por las desavenencias de su vértice político que siempre es Perón. Pero aun cuando éste desautorice -o en el peor de los casos- denosté o expulse a sus huestes, éstas persistirán en su adhesión al líder exilado, elaborando distintas prácticas y argumentos que permitirán la cohesión de distintos grupos políticos en el

\footnotetext{
${ }^{4}$ Serge Berstein, "La cultura política", en Jean-Pierre Rioux y Jean-François Sirinelli, Para una historia cultural. México, Taurus, 1999, p. 402.

5 Ídem, p. 400.

6 Ídem, p. 401.

${ }^{7}$ Omar Acha, Historia crítica de la historiografía argentina: las izquierdas en el siglo XX. Buenos Aires, Prometeo Libros, 2009, p. 305.
} 


\section{La forja de la izquierda peronista como cultura política a través de la trayectoria de John W. Cooke}

entendimiento de que sin peronismo no hay revolución social posible en la Argentina. Y es en el plano del "rechazo", de la exclusión o de la desautorización en donde, en distintas ocasiones, se ponen en escena iniciativas creativas para seguir concibiendo al peronismo como una doctrina de liberación nacional.

\section{Cooke y la forja de una cultura política.}

En el entramado de esos nuevos sentidos que estructuran la IP, la incidencia de John William Cooke es fundamental para comprender la reformulación ideológica y política que fue adquiriendo un sector del peronismo durante el periodo de la proscripción. Varios autores han abordado su trayectoria política-intelectual rescatando distintos aspectos. Richard Gillespie analizó el devenir insurreccional del primer delegado de Perón, mientras que autores como Ernesto Goldar, Horacio Gonzalez, y Aritz Recalde abordaron su vínculo con el ex presidente exilado a través del examen de su intercambio epistolar. ${ }^{8}$ Ernesto Salas ha analizado el rol de Cooke en el entramado de la resistencia Peronista, mientras que German Gil ha realizado un abordaje del tipo fenomenológico de la izquierda peronista en el que el director de semanario De Frente tendría un rol destacado tanto en sus potencialidades revolucionarias como en sus déficits. ${ }^{9}$ En los trabajos de Miguel Mazzeo predomina la intención de intelectualizar el pensamiento del primer delegado de Perón en relación a diferentes teóricos de la tradición marxista como Gramsci o Luckás para resituar distintas dimensiones del legado político de Cooke en las discusiones contemporáneas de las izquierdas locales. ${ }^{10}$

No obstante, aquí se ensayará una perspectiva metodológica concerniente a examinar las prácticas desplegadas por Cooke, partiendo del entendimiento de que esas acciones fueron fundantes de nuevos entramados de experiencia, y que en el devenir de las mismas se fueron tramando nuevas formas de concebir el peronismo. Para lo cual, recuperamos las prescripciones realizadas por Simona Cerutti en relación al tratamiento de las fuentes en tanto constitutivas de una dimensión esencial de la experiencia de los actores, de sus formas de "afirmar sus derechos, de asentar sus pretensiones y finalmente de legitimar su conducta y obtener su

\footnotetext{
8 Richard Gillespie, Cooke. El peronismo alternativo. Buenos Aires, Cántaro, 1989; Ernesto Goldar John William Cooke y el peronismo revolucionario. Buenos Aires, CEAL, 1984; Horacio González, "La revolución en tinta limón. Recordando a Cooke”. Unidos, № 11/12, 1986; Aritz Recalde, El pensamiento de John William Cooke en las cartas a perón 1956-1966. Buenos Aires, Ediciones Nuevos Tiempos, 2009.

${ }^{9}$ Ernesto Salas, La resistencia peronista. La toma del frigorífico Lisandro de la Torre. Buenos Aires, Altamira, 2006; Gemán Gil, La izquierda peronista (1955-1974). Para una interpretación ideológica. Buenos Aires, CEAL, 1986, pp.30-36.

${ }_{10}$ Miguel Mazzeo, Cooke, de vuelta. El gran descartado de la historia argentina. Buenos Aires, La Rosa Blindada, 1999; John William Cooke, textos traspapelados. Buenos Aires, La Rosa Blindada, 2000; El Hereje. Apuntes sobre John William Cooke. Buenos Aires, Editorial El Colectivo, 2016.
} 
reconocimiento."11 Es decir, proponemos aproximarnos a las instancias de producción de las mismas, y describir tanto las intenciones inscriptas en ellas como los contextos que crean. Intentaremos vincular los textos de Cooke con los usos y prácticas que desarrolló en torno a ellos, en tanto entendemos que su legado contribuyó a resignificar los fines y alcances del movimiento peronista, e incluso señaló el rumbo político de generaciones posteriores que buscaron inscribirse en esa cultura política que colaboró a cimentar. ${ }^{12}$ Al respecto, resulta relevante no perder de vista el carácter generacional que las culturas políticas precisan para su consolidación en tanto tales. ${ }^{13}$

En lo que sigue, se pondrá en relieve esos lugares de disputa por el sentido del peronismo proscripto que comienzan a vislumbrarse en las prácticas desplegadas por Cooke, y se describirán las novedades ideológicas y políticas que expresan sus acciones a partir del examen de entrevistas, cartas a distintos referentes políticos y documentos políticos elaborados por el ex delegado de Perón. Se abordarán tres periodos significativos de su trayectoria política e intelectual. El primero de ellos abarca desde sus funciones como diputado durante el primer peronismo hasta su desplazamiento como representante personal de Perón en Argentina (1945-1958). El segundo, comprende desde 1959 hasta el final de su exilio en Cuba. En el tercero, se inicia con su retorno a la Argentina en diciembre de 1963, y finaliza con su fallecimiento en septiembre de 1968.

\section{Entre el Congreso y la proscripción}

Durante este periodo, la preocupación por la defensa de los intereses nacionales -o de lo "nacional"- marcó el pulso del pensamiento de Cooke, y señaló el trazo de su trayectoria política e intelectual, tal como puede apreciarse en su labor parlamentaria entre 1946 y 1952, en su rol como director de la revista De Frente, y en sus funciones como vicepresidente del Instituto de Investigaciones Históricas Juan Manuel de Rosas en 1954.

Como diputado se opuso desde su bancada a la ratificación del tratado de Chapultepec y a la carta de las Naciones Unidas, iniciativas a las que consideraba "una amenaza para la soberanía argentina."14 También impugnó las premisas propuestas en el Congreso de la productividad de 1955, e incluso su alegato sería citado décadas más tarde por los diputados peronistas de izquierda para oponerse al "Pacto social" impulsado por el peronismo gobernante en 1973. Desde el semanario De Frente, rechazó los acuerdos en ciernes entre el gobierno de Perón y la Standard Oil, al considerarlo nocivo para los intereses nacionales. ${ }^{15}$ Ya por

${ }^{11}$ Simona Cerutti, “«À rebrousse-poil»: dialogue sur la méthode”. Critique, vol. n 769-770, 6, 2011, p. 572. Agradezco a Mariana Grazón Rogé las sugerencias bibliográficas sobre historia pragmática.

${ }^{12}$ Nicolás Casullo, Peronismo. Militancia y crítica (1973-2008). Buenos Aires, Ediciones Colihue, 2008.

${ }^{13}$ Serge Berstein. "La cultura política” ..., Op. Cit., pp. 396-398.

${ }^{14}$ Richard Gillespie, Cooke. El peronismo..., Op. Cit., p. 22.

15 Ídem, p. 23. 


\section{La forja de la izquierda peronista como cultura política a través de la trayectoria de John W. Cooke}

entonces daba cuenta de sus conocimientos del marxismo, especialmente, en lo referido a las tesis sobre la concentración del capital, cuando afirmaba: "Marx se equivocó en muchas cosas, pero no en el planteamiento del problema de la concentración del capital. La crisis es inherente al sistema capitalista y la guerra también lo es. Tarde o temprano el capitalismo deviene en imperialismo."16 Aunque no compartía las prescripciones políticas de la tradición marxista, ${ }^{17}$ advertía que esa matriz teórica permitía comprender en términos estructurales los efectos de la dinámica capitalista sobre los intereses nacionales.

El golpe de estado de septiembre de 1955 marcó un momento de quiebre para el peronismo. Durante el período abierto por la autoproclamada "Revolución Libertadora", Cooke fue designado como delegado personal de Perón en noviembre de 1956. Desde Chile, meses después, organizó el Comando Adelantado y la División de Operaciones de la Resistencia con el objeto de coordinar los esfuerzos peronistas en pos de la recuperación del poder, e incidir en la coyuntura política impuesta por el gobierno dictatorial.

En esa dirección deben considerarse las directivas de Perón a votar en blanco en los comicios que se desarrollaron el 28 de julio de 1957 para elegir constituyentes, con los que la dictadura buscaba legitimar la derogación de la Constitución de 1949. Las misivas de Perón para sabotear los comicios fueron trasmitidas a través de su emisario a sus contactos locales. En el semanario De Frente, editado desde la clandestinidad gracias a las gestiones de Héctor Tristán, ${ }^{18}$ Mariano Massilm y Férmín Chávez; como también por intermedio del Centro de Escritores Intelectuales y Artistas del Pueblo (CEIPAP), organizado a instancias de José Castiñeira de Dios se difundieron las directivas de votar en blanco. ${ }^{19}$ En la tramitación de esos apoyos, Cooke también dejó trascender las novedades que la coyuntura de ese entonces creaba para renovar la dirección del peronismo. En ese sentido, resulta significativa la carta que dirige a Castiñeira de Dios en respuesta a su felicitación por haber sido designado como emisario del líder exiliado. En ella, expresaba:

\footnotetext{
16 Cooke, discurso parlamentario, Cámara de Diputados, Diario de Sesiones, 1949, Vol. V, p. 3480; idid., 1950, Vol. 1, p. 618, Reproducido en Richard Gillespie, Cooke. El peronismo ..., Op. Cit., p. 44.

17 Por entonces entendía "que para la realización integral de la revolución nacional sólo queda una vía, que es la vía de la realización legislativa por medio de los instrumentos jurídicos que la Constitución nos acuerda", Cooke, discurso parlamentario, Cámara de Diputados, Diario de Sesiones, 1946, Vol. 1, p. 300.

18 Tristán fue un dirigente metalúrgico. En marzo de 1956 se integró al Comando Nacional Peronista como representante del sector sindical. En la clandestinidad, consiguió una imprenta en Avellaneda desde la cual se editaron dos números de la revista. En esta etapa, la publicación funcionó como canal de difusión del Comando Superior y "órgano oficial del Movimiento Peronista en el 3er año de ocupación antipatria".

19 Este nucleamiento tenía por objeto expresar la adhesión de intelectuales y artistas con el peronismo resistente. Castiñeira de Dios fue el impulsor del periódico Línea dura, órgano de prensa del Comando Táctico y del delegado de Perón entre 1957 y 1958.
} 
El Jefe comprendió perfectamente que no podíamos volver a septiembre del '55, sino iniciar una nueva etapa (...) los viejos dirigentes hicieron lo que había de esperarse: Pactaron (o intentaron hacerlo), se desorientaron, fueron apóstatas, débiles, cobardes. La masa mantuvo una intransigencia absoluta, despreció las soluciones parciales y frente a la vacancia de viejos cuadros dirigentes, permitió que se abriesen paso los jóvenes con empuje y convicción doctrinaria. ${ }^{20}$

Se advierte aquí la percepción acerca del golpe de Estado del '55 como un factor "depurador" de la antigua comandancia que en el pasado había inhibido la configuración de "una dirección unificada". ${ }^{21}$ La etapa inaugurada por la autoproclamada Revolución Libertadora posibilitaba el surgimiento de nuevos cuadros de conducción que impidieran la claudicación de los principios doctrinarios del peronismo, y un recambio generacional acorde con las demandas de la hora, plasmada en la elección del General en favor de Cooke.

En ese contexto Cooke promovió el "voto en blanco" a instancias de Perón. Las mayorías que se expidieron en las elecciones constituyentes por el voto en blanco no dejaron dudas acerca de la continuidad de la incidencia del peronismo en cualquier convocatoria que instara al sufragio popular. ${ }^{22}$ Esa indicación no pasó desapercibida por el líder de la UCRI, Arturo Frondizi, quien con vistas a su postulación como presidente de la República en los comicios del 23 de febrero de 1958, inició las tratativas a través de Rogelio Frigerio, para lograr un acuerdo con Perón que le posibilitara el apoyo de los votantes peronistas. Cooke resultó un actor central en la consumación del pacto, a pesar del rechazo que esta tratativa generaba en los cuadros de conducción de la resistencia peronista. ${ }^{23}$

Ya en "Informe y Plan de acción" remitido a Perón a fines de agosto de 1957, Cooke advertía que no estaban dadas las condiciones para desencadenar un levantamiento insurreccional para la recuperación del gobierno peronista. ${ }^{24} \mathrm{Al}$ respecto, Melon Pirro ha advertido sobre la fragilidad del liderazgo de Cooke y sobre

\footnotetext{
${ }^{20}$ John W. Cooke, Textos traspapelados (1957-1961). Buenos Aires: La Rosa Blindada, 2000 [1957], p. 51.

${ }^{21}$ Esta cuestión fue reiterada semanas después en "El pueblo salió fortalecido", publicado en Columnas del Nacionalismo Marxista, $\mathrm{N}^{0} 2,1957$ p.29.

${ }^{22}$ En aquella jornada se contabilizaron 2.115 .861 votos en blanco, que representaron casi el $25 \%$ del padrón electoral, seguidos por los 2.206.524 votos obtenidos por la UCRP y los 1.847.603, en Julio C. Melon Pirro, El peronismo después del peronismo. Resistencia, sindicalismo y política luego del 55. Buenos Aires, Siglo XXI editores, 2009.
}

${ }^{23}$ Raúl Lagomarsino y César Marcos se pidieron expresamente en contra del acuerdo con Frondizi, pronunciándose a favor del voto blanco y del desarrollo de acciones insurreccionales. Entonces planteaban "El Gordo ignora las normas más elementales de la lucha insurreccional, aunque a vos te parezca lo contrario. Si así no fuera, no podría colocarse en la absurda postura electoral que ha tomado y que inexorablemente, ha de hundirlo. (...) Este es un proceso mental que se inicia en su ignoracia más básica. Lo demás lo hace su formación polítiquera, su excesiva vanidad personal, y su visión limitada y lastrada," Carta de Marcos a Lagomarsino, 12-X-1957, reproducida en Marta Cichero, Cartas peligrosas de Perón. Buenos Aires, Planeta, 1992, pp. 162-163.

24 John W. Cooke, Juan D. Perón, Correspondencia Perón- Cooke, Buenos Aires: Ediciones Papiro 1972 [1957], pp. 307-315. 


\section{La forja de la izquierda peronista como cultura política a través de la trayectoria de John W. Cooke}

las dificultades de Perón para controlar, desde el exilio, al conjunto de los actores que conformaban el heterogéneo movimiento. ${ }^{25}$ En relación al pacto con Frondizi, el historiador marplátense resaltó que la "decisión se tomó teniendo en cuenta, fundamentalmente, el riesgo de que otros sectores del peronismo acordaran por separado con ésta u otras fuerzas concursantes" profundizando un proceso de disgregación del peronismo ante la inminencia de las elecciones. ${ }^{26} \mathrm{El}$ acuerdo entre la cúpula del peronismo en el exilio y la dirección de la UCRI se mantuvo en secreto hasta mediados de 1959.

Hasta ese momento, las expectativas acerca de la derogación de las de las sanciones que aun recaían sobre el peronismo, condicionan las palabras y los gestos de la hora. Tal como se evidenció en el reportaje a Cooke realizado por Osiris Troiani para la revista Mayoría cuando el emisario de Perón expresaba: "Nosotros nos desplazamos en el ámbito legal si contamos con garantías para ello, pero si se nos cierra esa vía recurriremos a la política insurreccional." 27 Es decir, dejaba claro que la vía insurreccional era la opción residual que habilitaba el contexto de clausura institucional para la toma del poder, pero no era per se la elegida por el peronismo. Por otro lado, esa afirmación pone en tensión aquellas interpretaciones que advierten una especie de "esencialismo" revolucionario inmanente en Cooke, obviando las torsiones que demandó la política del movimiento en cada coyuntura. Tampoco está presente una interpretación del peronismo en términos clasistas cuando planteaba: "no somos un partido de clase, sino de integración nacional. Pero el peronismo debe ser un instrumento político de la clase trabajadora para lograr sus reivindicaciones", 28 e incluso advertía que la posibilidad de una nueva convergencia de la burguesía nacional en el movimiento, en tanto "esos sectores han comprendido su error. Y hoy nos apoyan". ${ }^{29}$ Un año después, esos sectores serían, junto con los trabajadores, parte del "Frente de liberación nacional" que convocaba a organizar desde las páginas de la revista Soluciones - de cuño comunista-, como alternativa al frondizismo gobernante. ${ }^{30}$

\section{Entre la derrota y la revolución}

Hacia fines de 1959 comienzan a manifestarse una serie de novedades en los escritos de Cooke. Resulta pertinente no perder de vista un conjunto de factores que

\footnotetext{
${ }^{25}$ Y agrega "buena parte de la correspondencia que mantuvieron Perón y Cooke en esos años constituye el diálogo epistolar entre un exiliado sin destino fijo y un prisionero o asilado que disponían de limitadas posibilidades de intervención en el proceso político argentino y que escribían incluso en una situación de vulnerabilidad personal", Julio C. Melón Pirro, El peronismo después..., Op. Cit, p. 234.

26 Ídem.

${ }^{27}$ John W. Cooke, Textos traspapelados ..., Op. Cit, p. 73.

28 Ídem, p. 74

29 Ídem, p. 79.

30 Ídem, p. 90.
} 
pudieron haber intervenido en ese proceso. En primer término, desde mediados de 1957 su Informe de Situación y Plan de acción había generado malestar en referentes de la resistencia como Marcos y Lagomarsino, quienes a partir de entonces se pronunciaron en abierta oposición al Comando Superior. ${ }^{31}$ Por otro lado, meses después de consumado el pacto con Frondizi, Perón decide desplazar a su antiguo emisario, y reemplazarlo por el Consejo Coordinador y Supervisor (CCyS) encargado ahora de la reorganización política del movimiento; una tarea que su primer delegado parecía, a su juicio, imposibilitado de poder realizar. ${ }^{32}$ La evaluación del ex presidente pareció confirmada luego de la toma del frigorífico Lisandro de la Torre en enero de 1959, evento que a pesar de su épica, había terminado por neutralizar las posibilidades de negociar con el gobierno frondizista la progresiva normalización del peronismo. Este diagnóstico era compartido por integrantes políticos y sindicales del CCyS, quienes juzgaban como irresponsable la participación de Cooke en la huelga. ${ }^{33}$

En ese contexto, el antiguo emisario intentó cimentar su posición en el interior del peronismo sirviéndose de una novedosa conjugación de distintos elementos ideológicos-narrativos que le permitieran sustentar sus diagnósticos y proyecciones políticas. El primer giro en ese sentido, pueden advertirse en la exposición que realizó en el "Congreso de la Liberación Nacional” convocado por la Confederación General del Trabajo en Buenos Aires, durante el mes de noviembre de 1959. ${ }^{34}$ Allí, por primera vez, enunció una formula discursiva que se repetirá en sus escritos posteriores: "la liberación nacional y la revolución social no son dos asuntos independientes o paralelos, sino un solo problema indivisible." 35 Esta formulación, manifiesta un cambio de posición respecto a las proyecciones del peronismo clásico, en tanto su programa ya "no puede limitarse a una restauración de esas conquistas, sino que debe instaurar un nuevo orden social que supere al de la Constitución de 1853 y también al de la Constitución de 1949", más aún "el programa revolucionario de 1945 no puede ser el programa revolucionario de 1959". 36

Consideraba entonces que el problema nodal de la coyuntura política local era la lucha de clases existente en la Argentina. Por lo cual, "querer solucionar los problemas de ella derivados por medio de fórmulas conciliadoras es creer en la magia negra y ser tan reaccionarios como los que niegan su existencia." Las soluciones para alcanzar la liberación argentina ya no podían plantearse a través de

\footnotetext{
${ }^{31}$ Marta Cichero, Cartas peligrosas..., Op. Cit., pp.160-178.

${ }^{32}$ Julio C. Melon Pirro "Después del partido y antes del partido: el Consejo Coordinador y Supervisor del Peronismo", en José C. Chiaramonte; Herbert S. Klein (coord.) El exilio de Perón. Buenos Aires, Sudamericana, 2017, pp.209, 213

33 Ídem, pp. 219-222. Acerca de los posicionamientos de Cooke en relación con la huelga véase Roberto Baschetti, Documentos de la resistencia peronista. Buenos Aires, De la Campana, 1997, pp. 71-80.

${ }^{34}$ La trascripción de la exposición de Cooke fue publicada en el folleto La lucha por la Liberación Nacional, Buenos Aires, Fundación Scalabrini Ortiz, 1960.

35 Ídem, p. 6, cursivas en original.

36 Ídem.
} 


\section{La forja de la izquierda peronista como cultura política a través de la trayectoria de John W. Cooke}

la conciliación de clases propuesta por el peronismo sino a partir de la eliminación de las formas económicas a través de las cuales éstas se estructuraban antagónicamente. No obstante, advertía que "el estadio económico de nuestro país rechaza como utópica la solución de la dictadura del proletariado," por lo cual debía de articularse un Frente de Liberación Nacional policlasista, en el que la clase obrera fuera "el eje sobre el cual se apoyarán todas las fuerzas nacionales la primera avanzada y el último baluarte de las reivindicaciones nacionales."37

Durante su estadía en Cuba, Cooke tramitó una nueva legitimidad que se articuló -en parte- como testigo participante de la consolidación de un régimen de liberación nacional. Desde allí, reclutó jóvenes provenientes de distintas tradiciones políticas e ideológicas para que realizaran entrenamiento revolucionario, ${ }^{38}$ al mismo tiempo, que envió distintos mensajes a sus contactos políticos e intelectuales en Argentina, actuando como una suerte de traductor de la experiencia cubana de la cual participa. También intentó convencer a referentes del nacionalismo argentino nucleados en la Fundación Scalabrini Ortiz ${ }^{39}$ y en el Instituto de Investigaciones Históricas Juan Manuel de Rosas sobre la importancia de Cuba en la lucha contra el imperialismo. ${ }^{40}$ Además intentó convencer a Perón sobre la relevancia de la gesta cubana para el peronismo. ${ }^{41}$

En esas comunicaciones planteaba que el triunfo de Castro residió en comprender "que [la] acción de las masas debía basarse en el abandono de los métodos del pasado y en el desprecio por el electoralismo." 42 Cooke estaba convencido, a la luz de la experiencia cubana, que "cualquier tentativa de realizar una lucha de liberación nacional dentro de los carriles de la seudo legalidad burguesa es un contrasentido." $43 \mathrm{Su}$ apuesta era entonces la formación de un "frente de liberación nacional" en donde se diera la "unión e incorporación progresiva de distintos sectores a una lucha por la recuperación integral, es decir, que incluye la soberanía nacional del país y la revolución social como partes de un proceso indivisible" 44

En la correspondencia con el poeta Vicente Trípoli, le solicita que la Fundación Scalabrini Ortiz se comprometa en "la obligación de marcar una línea ideológica y de lucha, así como formar cuadros para la lucha que en este último año

\footnotetext{
37 Ídem. P. 7.

38 "Carta al compañero «Alhaja»", John W. Cooke, Artículos periodísticos, reportajes, cartas y documentos: Tomo III de las Obras completas de John W. Cooke. Buenos Aires, Colihue, 2015 [1961], p. 49-52.

39 La fundación fue creada en 1959 en homenaje a Raúl Scalabrini Ortiz, fallecido ese mismo año, a instancias de Miguel Unamuno, Leopoldo López Frostier, José Maria Rosa, y Vicente Trípoli.

40 “Carta a Vicente Trípoli”, Ídem, p. 43-44, 53-70; “Carta a Héctor Tristán”, Ídem, p. 45-47, “Carta a Juan José Hernandez Arregui”, Ídem, p. 90-95.

41 “Carta a Perón, julio de 1961", reproducida en John W. Cooke, Juan D. Perón, Correspondencia Perón-Cooke: Tomo II. Buenos Aires, Gránica,1973, p. 83.

42 John W. Cooke, Artículos periodísticos ..., Op. Cit., p. 41.

43 Ídem, p. 42.

44 Ídem.
} 
ha sufrido vergonzosos retrocesos". ${ }^{45}$ Los insta a actuar en la formación de cuadros de revolucionarios para desplazar a los burócratas del peronismo, e incluso los convoca a "transformarse en vanguardia ideológica del movimiento." 46 Además, insiste sobre la necesidad de que los nacionalistas nucleados en torno a la Fundación se solidaricen expresa y públicamente con Cuba.

Los argumentos esgrimidos para convencer a su interlocutor intentan resaltar la virtual amenaza que la gesta cubana representaba para el imperialismo yanqui. Desde su perspectiva, la revolución antillana daba cuenta de que "el mundo ha dado un vuelco definitivo a favor de los pueblos. El hecho de que, a pesar de sus esfuerzos concentrados, los imperialistas norteamericanos sean cada día más impotentes frente a Cuba es la prueba más irrefutable de ello."47 Este juicio, fundado en el fracaso de la invasión estadounidense a Bahía de Cochinos, parecía indicar el camino para emprender la liberación continental de las garras del imperialismo. Por ello, consideraba que estaban dadas las condiciones para el triunfo de la revolución en la región. Para ese diagnóstico contaba con distintos elementos. A escala internacional, Estados Unidos no podía avanzar sobre Cuba a raíz del apoyo brindado por la Unión Soviética. Un avance en esa dirección en plena Guerra Fría, podía implicar una declaración de guerra indirecta. A escala local, Argentina contaba con el movimiento obrero más avanzado de toda Latinoamérica. En su visión, lo que faltaba era la preparación de cuadros revolucionarios que condujeran el proceso, y una organización estructurada en torno a definiciones estratégicas que contaran con el beneplácito de Perón. Sin cuadros de conducción con la debida formación para la tarea de organización del pueblo en armas, el impulso terminaría frustrado.

En agosto de 1961 envía a Trípoli un manual de discusión política. En el texto se evidencia la percepción de Cooke respecto a la inminencia de la revolución y a la necesidad de capitalizar el momento de mayor debilidad del imperialismo yanqui luego de la frustrada invasión de Playa Girón. Según su visión, la imperiosa clarificación política, ideológica y doctrinaria era la tarea fundamental del peronismo por distintas razones. La primera de ellas era la consideración de que "la masa peronista no puede quedar siempre librada a su intuición y madurez política", sino que precisaba ser guiada por la senda revolucionaria. ${ }^{48}$ La segunda cuestión, era la problemática indefinición de la doctrina peronista, que terminaba cercenando "la unidad partidaria y popular, nos enfrenta con aliados reales y nos hace servir a los planes del enemigo." 49 La indefinición política del peronismo tergiversaba la verdadera sustancia revolucionaria del movimiento, y facilitaba la emergencia de direcciones burocráticas que manipulaban los mandatos de Perón en "beneficio

\footnotetext{
45 Ídem, p. 44.

46 Ídem, p. 53-54.

47 Ídem.

48 Ídem, p. 55.

49 Ídem, p. 56.
} 


\section{La forja de la izquierda peronista como cultura política a través de la trayectoria de John W. Cooke}

propio", desvirtuando el sentir y el hacer de las masas en su camino hacia la liberación. ${ }^{50}$

Esa última cuestión se expresó claramente en la correspondencia que mantuvo con Perón en esos años. Tal vez, la insistencia respecto a la definiciones doctrinarias, acompañada de cuestionamientos sobre la conducción del peronismo, junto con las urgencias de la coyuntura local, hayan incidido en la discontinuidad de las respuestas del ex presidente. ${ }^{51}$ En 1962, en los albores de las elecciones legislativas y de gobernador que habilitaban la presentación de listas peronistas por primera vez desde 1955, Cooke le demanda al General: "Defina el movimiento como lo que es, como lo único que puede ser; un movimiento de liberación nacional, de extrema izquierda." 52

Llamativamente, meses después de la anulación de las elecciones, y en el contexto del congreso sindical celebrado en la localidad cordobesa de Huerta Grande, fue editado en Córdoba, a instancias de Peronismo de Acción Revolucionaria, el folleto "El peronismo, movimiento de izquierda?". No solo resulta llamativa la similitud del nombre de esta agrupación con aquella que organizará Cooke a su retorno a la Argentina, sino también, el contenido político de la publicación. Luego de evocar a Eva Perón, el prólogo avanza identificando los significados del peronismo como una fuerza de izquierda, en tanto "sinónimo de popular, de justo, de eliminación de los privilegios, de liquidación de todas las injusticias, de rompimiento con la penetración imperialista, de extirpación de la oligarquía, de formas sociales nuevas donde el trabajador sea un ser digno y no una simple pieza de engranaje de explotación capitalista." ${ }^{33}$ Esos significados eran los que condensaba el significante peronismo, por lo cual rechazaban la supuesta izquierdización del movimiento, concluyendo que "el peronismo nunca estuvo a la derecha -sinónimo de injusticia, de coloniaje, de fraude, de explotación, de beneficencia humillante, etc.-," en tanto se exclamaba "EL PERONISMO ES IZQUIERDA." ${ }^{4}$ En las siguientes páginas del panfleto, se reproducen fragmentos de distintos discursos de Perón y del texto de Cooke "La lucha por la liberación nacional" con el objeto de sustentar las afirmaciones antes esgrimidas. Las últimas páginas son ocupadas por declaraciones de Andrés Framini, a quien se lo presenta como "Gobernador electo de la provincia de Buenos Aires y Secretario General de la Asociación Obrera Textil", seguido del subtítulo "No hay salida nacional dentro del sistema capitalista".

Dos cuestiones centrales iniciadas y difundidas por Cooke crecerán en intensidad y en organicidad a lo largo de la década del '60. Por un lado, la introducción del ideario marxista para redefinir los fines y alcances del movimiento

\footnotetext{
50 Ídem, p. 57.

51 El dialogo epistolar entre Perón y Cooke, recién se restablecerá en agosto de 1964 de manera intermitente.

52 Correspondencia Perón-Cooke..., Op. Cit., p. 222.

53 Peronismo de Acción Revolucionaria, El peronismo, movimiento de izquierda?, archivo CEDINCI.

54 Ídem, Mayúsculas en original.
} 
proscripto, habilitó una diferenciación discursiva respecto del peronismo clásico, a la vez que posibilitó el despliegue de diversos argumentos para posicionarse frente a otros sectores en pugna por el liderazgo del movimiento. Asimismo, permitió recategorizar las críticas hacia la burocracia peronista, ya no en términos "morales" como ha establecido James en Resistencia e integración, ${ }^{55}$ sino por su carácter de clase. Por otro lado, luego de ser desplazado como Delegado Nacional del Comando Superior del peronismo, las acciones de Cooke se dirigieron a crear alternativas críticas a las emanadas por Perón y a cimentar nuevas redes con referentes de otras fuerzas políticas. Lo cual implicó la elaboración de nuevas modalidades de intervención política por fuera de las estructuras formales del movimiento, aunque esto nunca implicara una renuncia a identificarse con el peronismo ni a actuar en él. 56

El análisis de sus prácticas indica la intención de influir sobre distintos actores, tanto en el interior como en el exterior del peronismo, que anticiparon modalidades de participación política que persistirán en el peronismo durante la década siguiente. La iniciativa forjada por el Movimiento Revolucionario Peronista (MRP) en agosto de 1964, difundida a través de las páginas de la revista Compañero, es un ejemplo de ello. ${ }^{57}$ Sin embargo, consideramos que su proceso formativo ya estaba en marcha. Basta revisar los contenidos de la publicación en el contexto de crisis interna del peronismo en relación a la disputa con Vandor por la conducción del Movimiento para advertir la similitud con los posicionamientos de Cooke en relación a la caracterización de la burocracia, pero también respecto a los alcances del peronismo revolucionario que desde ese semanario se difundieron. ${ }^{58}$ Varios de sus miembros habían recibido entrenamiento militar y político en Cuba por intermediación de Cooke, y sus textos políticos habían sido difundidos en los círculos militantes de ese entonces. En ese sentido, las iniciativas impulsadas por Cooke resultan relevantes en el estudio de la configuración simbólica de la izquierda peronista como cultura política, en tanto a través de su articulación se construyeron y actualización identidades en el interior del Movimiento proscripto que se procesaron de distinta manera durante el periodo.

\section{Las articulaciones posibles}

\footnotetext{
${ }^{55}$ Daniel James, Resistencia e integración: El peronismo y la clase trabajadora argentina, 1946-1976. Buenos Aires, Sudamericana, 1990.

56 Esa es la razón por la que se niega a integrarse al grupo CONDOR (Centros Organizados Nacionales de Orientación Revolucionaria), en cual participaban Hernandez Arregui, Rodolfo Ortega Peña, Eduardo L. Duhalde, Ricardo Carpani, Ruben Bortnik, Alberto Belloni, Oscar Balestieri y Rubén Borello. Eduardo Luis Duhalde; Rodolfo Ortega Peña, Felipe Vallese: proceso al sistema. Buenos Aires, Punto Crítico, 2002 [1965], p. 96-101.

57 Véase Marcelo Raimundo, "Compañero y los orígenes del Peronismo Revolucionario". Sociohistórica, №8, Universidad Nacional de La Plata. Facultad de Humanidades y Ciencias de la Educación. Centro de Investigaciones Socio Históricas, 2000.

58 Asimismo, varios de sus integrantes, una vez finalizada la experiencia del MRP mantuvieron vínculos con Acción Revolucionaria Peronista (ARP).
} 


\section{La forja de la izquierda peronista como cultura política a través de la trayectoria de John W. Cooke}

Muchas de las reformulaciones sobre el peronismo realizadas por Cooke permitieron el establecimiento de lazos y líneas de contacto con las interrogaciones de otros actores políticos que no necesariamente se identificaban con el movimiento proscripto. El ex delegado de Perón intentó tender puentes comunicantes con tradiciones políticas que hasta hacía poco tiempo se posicionaban en abierta oposición al peronismo.

La gesta cubana brindó, a su vez, un nuevo tamiz para evaluar la experiencia peronista y su salida abrupta del poder. También funcionó como ejemplo a emular, aunque atendiendo a las particularidades locales. Los gestos políticos de Cooke elaborados desde el exilio, no pueden escindirse -tal como plantea Campione -, del establecimiento de un dialogo en dos direcciones: hacia el interior del movimiento peronista, intentando su radicalización, o al menos, impulsar la estructuración en su seno de un sector de izquierda que debilite las direcciones "blandas"; y hacia afuera del movimiento, en dirección hacia otras izquierdas, que podrían actuar como potenciales aliadas en la revolución por hacer, e interpelándolas por la disputa de un mismo espacio político..$^{59}$ En ese sentido, los planteos esgrimidos por Cooke con el fin de reelaborar los contenidos revolucionarios del peronismo, junto con su participación - de cuerpo presente y actuante- en la causa cubana, posibilitaron la creación de vínculos con sectores de izquierdas que en los tempranos '60 atravesaban procesos de reformulación político e ideológico. ${ }^{60}$

Tal como puede observarse en las revistas Situación y Che, órganos de prensa del Partido Socialista Argentino de Vanguardia (PSAV). Desde sus páginas, jóvenes disidentes del Partido Socialista Argentino (PSA) expresaron la necesidad de articular su programa en vinculación con las reivindicaciones de los trabajadores argentinos que se identificaban con el peronismo. 61 En ese contexto, la predica de Cooke se convirtió en una referencia política e intelectual, que permitió

\footnotetext{
${ }^{59}$ Daniel Campione, “'Los comunistas somos nosotros': Cooke y el Partido Comunista Argentino", en Mazzeo, Miguel (compilador). Cooke, de vuelta. El gran descartado de la historia argentina, Buenos Aires, La Rosa Blindada, 1999.

${ }^{60}$ Las vinculaciones entre Cooke y los jóvenes integrantes del Partido Socialista Argentino de Vanguardia ha sido analizadas por M. Cristina Tortti en El 'viejo' Partido Socialista y los orígenes de la 'nueva' izquierda. Prometeo, Buenos Aires, 2009.

${ }^{61}$ Los nueve números de la revista Situación fueron publicados, entre marzo de 1960 y septiembre de 1961. Su consejo de redacción estaba integrado por Luis Bergonzelli, Buenaventura Bueno, Alexis Latendorf y Américo Parrondo. Che publicó 27 números entre octubre de 1960 y noviembre de 1961, bajo la dirección de Pablo Giussani. Su redacción, integrada por socialista e intelectuales de diversas procedencias políticas: Susana "Piri" Lugones, Carlos Barbé y Francisco Urondo; entre los socialistas, además de Giussani: Alexis Latendorf, Julia Constenla y Enrique Hidalgo. Entre sus colaboradores destacan Rodolfo Walsh y Eduardo Galeano. M. Cristina Tortti "La izquierda socialista, sus revistas y el "giro" hacia el peronismo (Argentina, 1955-1966)", en Hernán Camarero y Manuel Loyola (editores). Política y Cultura en los sectores populares y de las izquierdas latinoamericanas en el siglo XX, Santiago de Chile: Ariadna Ediciones, 2016, pp. 123-138.
} 
fundamentar los posicionamientos y proyecciones del PSAV en relación con el movimiento proscripción. ${ }^{62}$

Cooke evaluó la dinámica política del Partido Comunista de la Argentina (PCA) en relación con su capacidad para impulsar la insurgencia en el país, en el texto "Aportes para la crítica del reformismo en la Argentina", elaborado mediados de 1961 a instancias del gobierno revolucionario cubano. ${ }^{63}$. El núcleo su planteo despliega una crítica a las direcciones de un partido que, a pesar de autoproclamarse revolucionarias, no hacen más que converger en frentes electorales que neutralizan la potencialidad revolucionaria de las masas argentinas. Desde la perspectiva de Cooke, la conducción del PCA, aferrada a las líneas programáticas fijadas en el VII Congreso de la Internacional Comunista de 1935, replicaba constantemente la formación de frente populares con fines electorales como "táctica permanente que parece servir para todas las circunstancias." 64 Sin embargo, la inactualidad de esta dinámica clausuraba la posibilidad de establecer lazos con las fuerzas populares a las que el partido concebía de manera instrumental. ${ }^{65}$

Desde la óptica de Cooke, el PCA debía abandonar esa estrategia basada en la supuesta inexistencia de condiciones pre-revolucionares, en tanto éstas debían crearse a través de acciones concretas. ${ }^{66}$ El cuadro de situación en la Argentina presentaba un marco propicio para hacer estallar las contradicciones en pos de la revolución a través de la creación de situaciones insurreccionales que posibilitaran la toma del poder. La propuesta de Cooke para el PCA -como para el peronismo- era la reactualización de sus posicionamientos estratégicos en virtud de las urgencias de la hora. Para crear las condiciones desencadenantes de una situación insurreccional en la Argentina era necesario que las fuerzas políticas concebidas a sí mismas como revolucionarias -como era el caso del PCA-, rompieran los encorsetamientos doctrinales adversos a las resignificaciones impuestas por la praxis de los pueblos en la búsqueda por su liberación.

Cooke pensaba que el peronismo y el comunismo argentino podían compensar -de confluir en la senda insurreccional-, los déficits políticos que limitaban su potencialidad revolucionaria. Desde su visión, al peronismo le faltaba lo que al comunismo le sobraba: organización, y un corpus teórico claro que oriente el accionar de las masas hacia la revolución. El peronismo contaba con una amplia base de masas caracterizada por un activismo de tipo espontáneo que, aunque dinamizado por fuertes sentimientos nacionalistas y antiimperialistas, carecía de una perspectiva estratégica de transformación revolucionaria. Sin embargo, los

\footnotetext{
62 Pablo Giussani, "El socialismo: alternativa nacional”, Situación №1, marzo 1960; Enrique Hidalgo, "Hacia una política de izquierda integrada en las masas. Superar al peronismo, no destruirlo", Situación №7, diciembre 1960; “EL Movimiento de Liberación Nacional”, Situación №9, septiembre 1961.

${ }^{63}$ El texto fue publicado por primera vez en Pasado y Presente, $N^{0} 2 / 3$ (nueva serie), año IV, julio/ diciembre de 1973.

64 Ídem, p.376.

65 Ídem, p. 382.

66 Ídem.
} 


\section{La forja de la izquierda peronista como cultura política a través de la trayectoria de John W. Cooke}

planteos concretos del comunismo argentino, y la traducción de su pensamiento pretendidamente revolucionario en el terreno de la praxis, resultaban moderados, reformistas e incapaces de rebasar los límites del campo de batalla trazado por las clases dominantes. Esa era la razón por la cual el PCA -según Cooke-, en su situación actual, no podía ampliar su llegada a las masas. Refugiado en la autosuficiencia de proclamarse vanguardia del proletariado en base a la posesión de la "ciencia" del marxismo-leninismo, quedaba finalmente aislado de las gestas populares que se expresaban a través del peronismo. Por ello, postulaba la necesidad de la complementariedad teórica y práctica entre el peronismo y las fuerzas políticas que se autoproclaman revolucionarias, como era el caso del PCA. ${ }^{67}$

La cuestión sobre la relación entre teoría y praxis revolucionaria fue retomada en el texto "Bases para una política cultural revolucionaria", ${ }^{6}$ publicado en la Rosa Blindada. ${ }^{69}$ La exposición de Cooke se articuló a través de la relectura de los Manuscritos económicos filosóficos de 1844 y del concepto de alienación, insumos de los que se sirvió para criticar las lecturas deterministas y cientificistas de la obra de Marx impuesta por el dogmatismo stalinista, en detrimento del carácter humanista del marxismo. ${ }^{70}$ Justamente, la escisión del legado de Marx tenía efectos concretos sobre las proyecciones políticas que realizaban los actores que se identificaban con esa tradición. El régimen soviético bajo las órdenes de Stalin, fracturó la unidad entre la teoría y la praxis revolucionaria, reduciendo la primera al mero consignismo. ${ }^{71}$ Para restituir su unidad, "el conocimiento revolucionario" debía de nutrirse del "conocimiento de la práctica social" en tanto "guía para la práctica transformadora". ${ }^{72} \mathrm{Y}$ ese conocimiento implicaba al mismo tiempo la advertencia del carácter alienante del orden capitalista sobre la conciencia humana. De allí la concepción respecto a que toda política revolucionaria debía expresar un

\footnotetext{
67 Ídem, p.374.

68 "Bases para una política cultural revolucionaria", La Rosa Blindada, año I, $\mathrm{N}^{0}$ 6, 1965, Reproducido en John W. Cooke, Artículos periodísticos... p., 211-222. Kohan destaca "el lugar privilegiado que luego los jóvenes editores le conceden - nada menos que en una discusión sobre la cultura - a John William Cooke, quien, a pesar de tener vínculos con Hernández Arregui, construyó su lectura del peronismo desde una matriz mucho más ligada al marxismo historicista y humanista del Che Guevara (y también de Gramsci, Lefebvre y Lukács) que al ensayo clásico nacional-popular", Néstor Kohan, La Rosa Blindada, una pasión de los '60. Buenos Aires, La Rosa Blindada, p.26.
}

${ }^{69}$ Esta revista vinculada en sus inicios al PCA, apostaba a la construcción de una cultura contrahegemónica. La inclusión del texto de Cooke "dejaba sin argumentos tanto a los cultores del frente cultural laico-democrático-cientificista-progresista del stalinismo como a los del frente nacionalpopulista", Ídem, p. 42-41.

70 "Porque basta tener en cuenta cuál era la concepción de Marx sobre el conocimiento científico para que los Manuscritos y El Capital no sean los términos de una antinomia, ni siquiera de una rectificación visual sino expresiones de un pensamiento que se despliega en momentos que son constitutivos y no negaciones reciprocas", John William Cooke, Bases para una política cultural ..., Op. Cit, p. 220.

71 "El conocimiento teórico de la filosofía marxista suele no originar una práctica revolucionaria sino una actitud alienada pero con justificaciones prestigiosas", Ídem.

72 Ídem, p. 219. 
enlazamiento profundo entre teoría y praxis, resultante de "un desarrollo histórico de la autoconciencia crítica".

No obstante, la pretendida unidad entre teoría y praxis planteada por Cooke era discutida por León Rozitchner en su texto "La izquierda sin sujeto". ${ }^{73}$ En ese ensayo el filósofo argentino postulaba una respuesta crítica a las proyecciones del texto del delegado, aunque sin mencionarlo. ${ }^{74}$ Aquí cuestionaba la escisión no entre teoría y praxis, sino entre razón y sensibilidad revolucionaria. También advertía acerca de los inconvenientes que implicaba afirmar que el peronismo era la clave para pensar y hacer la revolución socialista. Para Rozitchner, la subjetividad nacida del peronismo obturaba cualquier proyecto emancipatorio del capital. Su invocación no conllevaba a la liberación, sino que reproducía las condiciones de un orden que desde el marxismo se buscaba erradicar. Esa emergencia popular que celebraba el antiguo emisario de Perón, no podía reclamar la erradicación del capital, porque su propia existencia dependía de su reproducción.

Sin embargo, Cooke consideraba que el peronismo era ese factor aglutinante de la clase obrera sin el cual ningún proyecto revolucionario podría gestarse. De allí, la necesidad de forjar las condiciones para que la unidad entre teoría praxis fueran una sola en la senda hacia el socialismo que sin el movimiento proscripto no podría lograrse.

\section{Tercer tiempo: el retorno}

Un tercer momento de la trayectoria de Cooke se desarrolla luego de su regreso a la Argentina, tras de cuatro años de exilio. Durante este periodo se autodefinirá como "ideólogo" del peronismo, aunque sin intenciones de formar parte de las estructuras de conducción del partido proscripto en virtud de su diagnóstico sobre la situación del movimiento: “El drama del país es que el peronismo, de esencia revolucionaria y antiimperialista, está dirigido por elementos de extrema derecha que no saben correctamente nada de lo que hay que saber para dirigir un movimiento popular". ${ }^{75}$ El fracaso del "operativo retorno" en diciembre de 1964, se presentaba como una prueba más en la larga cadena de argumentos esgrimidos por Cooke en su denuncia contra las direcciones burocráticas que dominaban el peronismo.

Para contrarrestar ese estado de situación y su posición marginal en la órbita del movimiento proscripto, impulsó en 1964 la organización de Acción Revolucionaria Peronista (ARP). En el proceso de formación de ARP se puede

\footnotetext{
${ }^{73}$ León Rozitchner "La izquierda sin sujeto", en Kohan, Néstor, La Rosa Blindada, una pasión de los '60, Buenos Aires: La Rosa Blindada, 1998 [1965], pp. 295, 296.

74 "En cuanto al artículo de La Rosa Blindada -señala Rozitchner- yo lo escribí para demostrarle que desde la perspectiva de los Manuscritos el peronismo era insostenible. Yo coincidía con Cooke en el rescate del marxismo humanista y antideterminista pero donde no podía coincidir era en que él no hubiese aplicado esas categorías al análisis del peronismo", Ídem, p.48.

${ }^{75}$ El Mundo, 27 de diciembre de 1963.
} 


\section{La forja de la izquierda peronista como cultura política a través de la trayectoria de John W. Cooke}

identificar la confluencia de distintos grupos. El núcleo de organización y de dirección estuvo constituido por Cooke y Alicia Eguren, Jorge Gil Solá, Carlos Lafforgue, Norberto Liffchitz, Roberto Sinigaglia, Héctor Tristán, Manuel Gaggero, ${ }^{76}$ entre otros. También estableció contactos con el grupo proveniente de la FARN, vinculado a Ángel Bengoéchea. Asimismo, la agrupación de Cooke mantenía buenas relaciones con Juan García Elorrio, Fernando Abal Medina y Norma Arrostito, vinculados a la revista Cristianismo y Revolución. ${ }^{77}$ El riñón sindical del ARP estuvo integrado por un grupo de militantes de base conformado por Domingo Blajakis, Raimundo y Rolando Villaflor, Francisco Alonso, Juan Carlos Zalazar y Ángel Taborda. Este grupo de militantes protagonizó un enfrentamiento con fracciones sindicales vandoristas en mayo de 1966, en el que fueron asesinados Blajakis, Zalazar, y el sindicalista Rosendo García. ${ }^{78}$

La intención del ARP era la de influir en los frentes sindical, político e ideológico en términos revolucionarios. Algunos de los posicionamientos de Cooke respecto a la cuestión sindical, pueden observarse en el texto "Acción Revolucionaria Peronista ante el Plenario de Tucumán". A través de esta declaración se plasmaba la posición de su organización ante el "Primer Congreso Nacional de las 62 Organizaciones de Pie junto a Perón" que se desarrolló en marzo de 1966 en la provincia de Tucumán. Escuchar a las "masas", afinar el diagnóstico de situación y elaborar líneas de acción conjunta a través del establecimiento de definiciones sobre el curso que debía de adoptar el peronismo eran los requisitos fundamentales para emprender la lucha contra el imperialismo. ${ }^{79}$ La lealtad a la impronta revolucionaria de Perón en su gesta contra el imperialismo debía ser el nexo coordinante de las fuerzas que convergían en su seno, e imponerse "por encima de los desencuentros transitorios o de las divergencias tácticas" para desplegar "las corrientes patrióticas de la revolución peronista" orientada en torno a "la fe en la acción de las masas."80

Meses después, el apoyo de distintos referentes políticos y sindicales del peronismo a la dictadura comandada por el Gral. Onganía recrudecieron sus críticas a las conducciones del movimiento. El desarrollo explicativo de esas concepciones se condensará en El peronismo y el golpe de estado. Informe a las bases (1966), y La

\footnotetext{
${ }^{76}$ Manuel Gaggero conoció a Cooke en Cuba en 1962, a donde concurrió para recibir entrenamiento militar. Posteriormente, Gaggero actuaría como enlace entre ARP y la Juventud Universitaria Peronista.

77 Esteban Campos, Cristianismo y Revolución. El origen de Montoneros. Violencia, política y religión en los 60. Buenos Aires, Edhasa, 2016, p. 140. En el segundo número de la revista Cristianismo y Revolución se publica el texto de Cooke "Definiciones", en el condensa varios de los argumentos que luego serán centrales en su libro El peronismo y el golpe de estado. Informe a las bases.

${ }^{78}$ Este episodio fue posteriormente investigado por Rodolfo Walsh. Los avances de la pesquisa fueron publicados en seis entregas en el Semanario CGT, entre el 16 de mayo de 1968 y el 27 de junio de 1968 Alicia Eguren fue quien contactó al periodista con los hermanos Villaflor, ambos sobrevivientes del enfrentamiento.

${ }^{79}$ John William Cooke, “Acción Revolucionaria peronista ante el plenario de Tucumán”, marzo de 1966, p. 3.

80 Ídem.
} 
revolución y el peronismo (1967). ${ }^{81}$ En estos escritos desplegó un conjunto de prescripciones ya presentes en sus textos anteriores, aunque ahora condicionados por el nuevo golpe de estado.

En esos textos planteaba que el entendimiento sobre el significado fundamental del primer peronismo consistió en haber posibilitado la vertebración de la nacionalidad en torno a la clase proletaria. El 17 de octubre de 1945 había significado un vuelco en la política argentina; desde entonces los trabajadores y trabajadoras argentinas reclamaban para sí un lugar protagónico en la dirección del Estado, expresándose a través de Perón. ${ }^{82}$ Allí, entonces, residía la importancia del peronismo para las gestas populares: en su capacidad de aunar voluntades dispersas y encauzarlas en pos del bienestar colectivo. A la vez, expresaba la manifestación histórica de un nuevo estadio en su realización como nación. El pueblo, concebido como alteridad crítica al sistema de dominación impuesto por las élites extranjerizantes, constituía, en esta clave de pensamiento, la fuerza activa que a través del peronismo vehiculizaba su misión histórica de liberar otra vez la patria, estableciendo así un nexo ineludible entre los descamisados de octubre del ' 45 y las fuerzas populares del ayer, aquellas que habían hecho posible la primera independencia y la Federación decimonónica. Como en el pasado, la liberación nacional era inescindible de la soberanía popular que se plasmaba en el peronismo. Por eso planteaba "Perón no sacó de la galera al proletariado ni inventó las contradicciones: pero las hizo aflorar y dio formas orgánicas de enfrentamiento con la burguesía." 83 Asimismo, desde 1955 -siguiendo a Cooke-, ya no había, lugar para conciliación de clases propuesta por el primer peronismo. A partir de entonces la burguesía nacional no podía ser considerada como una clase progresista en función de su defección ante el imperialismo. ${ }^{84}$

La relectura del contexto abierto en 1955 ponía en evidencia la falsedad del dilema peronismo-antiperonismo, ya que detrás de su enmascaramiento político ocultaba la contradicción entre fuerzas sociales antagónicas. De allí, la consideración sobre la "antinomia «peronismo- antiperonismo»", en realidad expresaba "la forma concreta en que se da la lucha de clases en este periodo de nuestro devenir", 85 siendo el peronismo "la expresión de la crisis global del sistema burgués argentino, pues representa a las clases sociales cuyas reivindicaciones no pueden lograrse en el marco del institucionalismo actual." 86 Desde esta perspectiva, ningún proyecto revolucionario por fuera del peronismo podría expresar acabadamente las contradicciones subyacentes de la sociedad argentina, ya que éstas eran

\footnotetext{
${ }^{81}$ El primero de estos textos fue editado por Acción Revolucionaria Peronista. El segundo de los títulos mencionado circuló en una versión mimeografiada entre los militantes de la agrupación. En 1968 fue publicado como folleto por Ediciones A.R.P.

${ }^{82}$ John William Cooke, Peronismo y revolución; apuntes para la militancia: la lucha por la liberación nacional/ informe a las bases. Tomo V de las Obras completas de John William Cooke, Buenos Aires:

Colihue, 2014 [1966], p. 78-79.

83 Ídem, p. 80.

84 Ídem, p. 84

85 Ídem, p.81.

86 Ídem, p. 82, cursivas es en original.
} 


\section{La forja de la izquierda peronista como cultura política a través de la trayectoria de John W. Cooke}

constitutivas del movimiento proscripto y de su lugar en la historia por la emancipación de los pueblos.

El planteo del antiguo delegado de Perón advertía la imposibilidad del retorno del peronismo al poder del estado dentro del orden político institucional vigente, dado que la coyuntura actual daba cuenta del agotamiento de las experiencias democráticas burguesas para resolver los problemas de la hora. ${ }^{87}$ Esta convicción obligaba a los peronistas a elaborar nuevas soluciones políticas. En ese sentido, el diagnóstico sobre la situación del peronismo y su dirigencia evidenciaba la necesidad de actualizar los fines y alcances del movimiento lo cual, en la lectura de Cooke, implicaba abandonar los mojones doctrinales del primer peronismo para evitar el desfasaje entre la doctrina y las demandas políticas y sociales de las fuerzas sociales que convergían en su seno. El peligro de la "escoliosis" política era una amenaza para la representatividad del movimiento en relación con su rol histórico. La advertencia para el peronismo era entonces, la de no quedar atrapado en los entreveros institucionalistas que el orden burgués impone para su reproducción, y reencauzar su potencia revolucionaria para iniciar el camino hacia la emancipación nacional.

Cooke propone dos soluciones: redefinir los lineamientos doctrinarios del peronismo para conducir eficazmente el espontaneísmo hacia la senda revolucionaria; y organizar cuadros de conducción que permitan realizar las demandas populares por el retorno del peronismo, y con este, alcanzar la revolución nacional y social. ${ }^{88}$ Esas tareas eran las concernientes de ARP, en su condición de vanguardia revolucionaria de "la izquierda del peronismo",89 influyendo sobre las estructuras políticas y sindicales del Movimiento para direccionarlo en pos del "esfuerzo liberador" en el que "la juventud con formación intelectual y técnica cumplirá funciones de valor inapreciables".90 No obstante las proyecciones realizadas, la muerte de Cooke el 20 de septiembre de 1968 señaló el comienzo del ocaso de la experiencia agitativa y organizativa de ARP, ${ }^{91}$ aunque no el fin de la incidencia de sus iniciativas y prescripciones sobre el peronismo. ${ }^{92}$

\footnotetext{
${ }^{87}$ John William Cooke, Artículos periodísticos,..., Op. Cit. P. 255.

88 Ídem, p. 58.

${ }^{89}$ Acción Revolucionaria Peronista, Boletín Interno $\mathrm{N}^{0} 1$, diciembre de 1966, p. 15, cursivas en original.

90 Ídem.

${ }^{91}$ Varios de sus integrantes confluyeron posteriormente en las Fuerzas Armadas Peronistas (FAP) y en el peronismo de base.

92 Peronismo y socialismo, $\mathrm{n}^{0} 1$, 1973, pp. 20; José Pablo Feimann "Cooke: peronismo e historia". Envido, Año III, No 8, marzo de 1973, pp. 16-24; Horacio González, "Estado planificador, movilización popular, socialismo nacional". Envido, Año II, N ${ }^{0} 5$, marzo de 1972, pp. 25-40; "Gorilas, integracionistas y lanusardos". Envido, Año II, $\mathrm{N}^{0} 7$, octubre de 1972; "La respuesta peronista a las elecciones trampa". Envido, Año II, ${ }^{0} 8$, marzo de 1973 , pp. 6-15. La incidencia del pensamiento de Cooke en la obra temprana de González también puede apreciarse en "Prólogo. Para nosotros Antonio Gramsci", en Gramsci, Antonio: El príncipe moderno y la voluntad nacional-popular. Buenos Aires, Puentealsina, 1972. Véase también Juan Carlos Portantiero, "Introducción a texto inédito de Cooke". Pasado y Presente, $\mathrm{N}^{0}$ 2/3 (nueva serie), año IV, 1973, p. 372.
} 


\section{Reflexiones finales}

El transito ideológico realizado por Cooke estuvo nutrido por una sedimentación de diversas experiencias: su actividad parlamentaria durante el primer peronismo, la comandancia del peronismo local en el periodo inicial de la proscripción, las discrepancias con Perón acerca del rumbo que debía de adoptar el movimiento prohibido, el exilio cubano, y la intención de impulsar la opción revolucionaria del peronismo como movimiento de liberación nacional anticapitalista.

El esfuerzo intelectual y político de Cooke, desde su estadía en Cuba hasta el fin de sus días, estuvo dirigido a superar el divorcio entre pensamiento y acción, o al menos a acortar distancias, y encontrar los medios necesarios para vertebrar al gigante. De allí la urgencia de la imprescindible actualización doctrinaria del peronismo para evitar su desfasaje respecto de los problemas que afectaban a la sociedad argentina durante la década del '60. Pero la reformulación doctrinaria que promovió el ex delegado de Perón no debía realizarse en cualquier dirección, sino en aquella alumbrada por los postulados teóricos del marxismo. La obra de Marx señalaba que el capital y sus reglas dominan por completo cualquier entendimiento sobre los destinos de las naciones. También planteaba la imposibilidad de reeditar la experiencia peronista en los términos del periodo 1945-1955. La alianza democrática-burguesa ya no alcanzaba para subvertir la amenaza que significaba para los intereses nacionales el despliegue del capital monopólico en el país. La defensa de la nación y de las clases populares que se expresaban a través del peronismo, solo podrían lograrse a través de la lucha insurreccional.

Dicho entendimiento deviene de la advertencia acerca de la potencialidad revolucionaria del peronismo en tanto encarnación de la nación y del sentir del pueblo oprimido. Su defensa y su triunfo demandaba una definición ideológica y estratégica como movimiento de liberación nacional. La toma del poder en términos revolucionarios sólo se podría efectuar a través del peronismo proscripto, única fuerza política con capacidad para movilizar a las masas. El déficit del Movimiento estaba en sus conducciones, por lo cual también era preciso formar cuadros de conducción revolucionaria que permitieran superar a las dirigencias burocráticas para emprender el camino insurreccional.

Observamos que las referencias a las proyecciones política de Cooke en revistas de militantes jóvenes disidentes de las izquierdas tradicionales, la convocatoria a publicar en una revista vinculada con el PC como la Rosa Blindada, como la respuesta de un intelectual de izquierda como Rozitchner pueden considerarse como índices de las nuevas redes intelectuales cultivadas por el delegado desde su exilio cubano. También permiten advertir el lugar de relevancia que comienza adquirir su prédica respecto a la necesidad de considerar la izquierda peronista como el vector de la revolución por hacer, y una vía a través de la cual John William Cooke tramó una nueva legitimidad. Ya no exclusivamente como dirigente 


\section{La forja de la izquierda peronista como cultura política a través de la trayectoria de John W. Cooke}

político del movimiento proscripto, sino también como ideólogo de un sector del peronismo del cual forjó sus contornos, los cuales permitieron la actualización identidades tanto dentro como fuera del peronismo que se procesaron de distinta manera durante el periodo.

\section{Bibliografía}

Aritz Recalde, El pensamiento de John William Cooke en las cartas a perón 1956-1966. Buenos Aires, Ediciones Nuevos Tiempos, 2009.

Daniel Campione, “'Los comunistas somos nosotros': Cooke y el Partido Comunista Argentino", en Mazzeo, Miguel (compilador). Cooke, de vuelta. El gran descartado de la historia argentina, Buenos Aires, La Rosa Blindada, 1999.

Daniel James, Resistencia e integración: El peronismo y la clase trabajadora argentina, 1946-1976. Buenos Aires, Sudamericana, 1990.

Eduardo Luis Duhalde; Rodolfo Ortega Peña, Felipe Vallese: proceso al sistema. Buenos Aires, Punto Crítico, 2002.

Ernesto Goldar John William Cooke y el peronismo revolucionario. Buenos Aires, CEAL, 1984.

Ernesto Salas, La resistencia peronista. La toma del frigorífico Lisandro de la Torre. Buenos Aires, Altamira, 2006.

Esteban Campos, Cristianismo y Revolución. El origen de Montoneros. Violencia, política y religión en los 60. Buenos Aires, Edhasa, 2016.

Gemán Gil, La izquierda peronista (1955-1974). Para una interpretación ideológica. Buenos Aires, CEAL, 1986.

Horacio González, "Estado planificador, movilización popular, socialismo nacional”. Envido, Año II, N05, Buenos Aires, marzo de 1972.

Horacio González, "Gorilas, integracionistas y lanusardos". Envido, Año II, N ${ }^{0} 7$, octubre de 1972.

Horacio González, "La respuesta peronista a las elecciones trampa". Envido, Año II, $\mathrm{N}^{0} 8$, marzo de 1973.

Horacio González, "Prólogo. Para nosotros Antonio Gramsci”, en Gramsci, Antonio: El príncipe moderno y la voluntad nacional-popular. Buenos Aires, Puentealsina, 1972. 
Horacio González, "La revolución en tinta limón. Recordando a Cooke". Unidos, N 11/12, 1986.

Jean François Sirinelli, "Elogio de lo complejo", en Jean-Pierre Rioux y Jean-François Sirinelli, Para una historia cultural. México, Taurus, 1999.

John W. Cooke, Juan D. Perón, Correspondencia Perón- Cooke, Buenos Aires: Ediciones Papiro 1972 [1957]

John W. Cooke, Juan D. Perón, Correspondencia Perón-Cooke (1973) Tomo II. Buenos Aires, Gránica, 1973.

John William Cooke, Artículos periodísticos, reportajes, cartas y documentos: Tomo III de las Obras completas de John W. Cooke. Buenos Aires, Colihue, 2015.

John William Cooke, Peronismo y revolución; apuntes para la militancia: la lucha por la liberación nacional/ informe a las bases. Tomo V de las Obras completas de John William Cooke, Buenos Aires: Colihue, 2014.

José Pablo Feimann "Cooke: peronismo e historia". Envido, Año III, n ${ }^{0} 8$, marzo de 1973.

Juan Carlos Portantiero, "Introducción a texto inédito de Cooke". Pasado y Presente, $\mathrm{N}^{0} 2 / 3$ (nueva serie), año IV, 1973.

Juan Luis Besoky. La derecha peronista. Prácticas políticas y representaciones (19431976). La Plata, Tesis de doctorado, 2015.

Julio C. Melon Pirro, El peronismo después del peronismo. Resistencia, sindicalismo y política luego del 55. Buenos Aires, Siglo XXI editores, 2009.

Julio C. Melon Pirro "Después del partido y antes del partido: el Consejo Coordinador y Supervisor del Peronismo", en José C. Chiaramonte y Herbert S. Klein (coordinadores). El exilio de Perón. Buenos Aires, Sudamericana, 2017.

León Rozitchner "La izquierda sin sujeto", en Kohan, Néstor, La Rosa Blindada, una pasión de los '60, Buenos Aires: La Rosa Blindada, 1998 [1965].

Marcelo Raimundo, "Compañero y los orígenes del Peronismo Revolucionario". Sociohistórica, №8, Universidad Nacional de La Plata. Facultad de Humanidades y Ciencias de la Educación. Centro de Investigaciones Socio Históricas, 2000.

M. Cristina Tortti en El 'viejo' Partido Socialista y los orígenes de la 'nueva' izquierda. Prometeo, Buenos Aires, 2009.

M. Cristina Tortti "La izquierda socialista, sus revistas y el "giro" hacia el peronismo (Argentina, 1955-1966)”, en Hernán Camarero y Manuel Loyola (editores). Política y Cultura en los sectores populares y de las izquierdas latinoamericanas en el siglo XX, Santiago de Chile: Ariadna Ediciones, 2016.

Marta Cichero, Cartas peligrosas de Perón. Buenos Aires, Planeta, 1992. 


\section{La forja de la izquierda peronista como cultura política a través de la trayectoria de John W. Cooke}

Miguel Mazzeo, Cooke, de vuelta. El gran descartado de la historia argentina. Buenos Aires, La Rosa Blindada, 1999.

Miguel Mazzeo, John William Cooke, textos traspapelados. Buenos Aires, La Rosa Blindada, 2000.

Miguel Mazzeo, El Hereje. Apuntes sobre John William Cooke. Buenos Aires, Editorial El Colectivo, 2016.

Néstor Kohan, La Rosa Blindada, una pasión de los '60. Buenos Aires, La Rosa Blindada, 1998.

Nicolás Casullo, Peronismo. Militancia y crítica (1973-2008). Buenos Aires, Ediciones Colihue, 2008.

Norberto Galasso Cooke de Perón al Che. Una biografía política. Buenos Aires, Ediciones Nuevos Tiempos, 2005.

Omar Acha, Historia crítica de la historiografía argentina: las izquierdas en el siglo XX. Buenos Aires, Prometeo Libros, 2009.

Richard Gillespie, Cooke. El peronismo alternativo. Buenos Aires, Cántaro, 1989.

Roberto Baschetti, Documentos de la resistencia peronista. Buenos Aires, De la Campana, 1997.

Serge Berstein, "La cultura política”, en Jean-Pierre Rioux y Jean-François Sirinelli, Para una historia cultural. México, Taurus.

Simona Cerutti, “«À rebrousse-poil»: dialogue sur la méthode". Critique, vol. n 769770, 6, 2011.

Recibido: 01/05/2017

Evaluado: 25/05/2017

Versión Final: 19/07/2017 